\title{
Injuries in recreational curling include head injuries and may be prevented by using proper footwear
}

\author{
D. K. Ting, MD (1); R. J. Brison, MD, MPH (2)
}

This article has been peer reviewed.

Tweet this article

\begin{abstract}
Introduction: Our study examines a recreational curling population to describe patterns of injury occurrence, estimate risk of injury and to gauge attitudes towards equipmentbased prevention strategies.
\end{abstract}

Methods: In a retrospective case series, we queried the Canadian Hospitals Injury Reporting and Prevention Program (CHIRPP), a national injury surveillance database, for curling injuries entered between 1993 and 2011. Kingston General Hospital and Hotel Dieu Hospital provide the two Kingston, Ontario, sites for emergency department (ED) care and participate in CHIRPP. Each retrieved entry underwent a chart review. A secondary survey was mailed to select individuals who had experienced curling injuries to solicit details on their injury and attitudes towards equipment to prevent injury. We used descriptive statistics for rates and proportions.

Results: Over $90 \%$ of acute curling injuries resulted from a fall, and $31.7 \%$ were head impacts. We found that acute injuries requiring ED presentation occur at a rate of approximately 0.17 per 1000 athlete-exposures (95\% CI: 0.12-0.22). The secondary survey was completed by $54 \%$ of potential respondents. Of survey respondents, $41.3 \%$ attributed their fall to a lack of proper footwear and $73.5 \%$ of respondents agreed with mandatory sport-specific footwear as a prevention strategy, but only $8 \%$ agreed with mandatory helmet wear.

Conclusions: Although curling injuries requiring medical care are not common, head injuries make up a large proportion. Mandated use of appropriate footwear appears to be the most effective prevention strategy, as well as the measure deemed most acceptable by players.

Keywords: curling, athletic injury, brain concussion, injury prevention, emergency medicine

Key findings

- Curling is a popular sport in Canada yet patterns of injury in recreational curlers have not been described.

- Our study examined the mechanism and anatomical nature seen with injuries in recreational curlers who presented for care to an emergency department setting in Kingston, Ontario, that participates in the Canadian Hospitals Injury Reporting and Prevention Program.

- Over $90 \%$ of injuries were related to uncontrolled falls on ice with head injuries (including concussions) and upper limb fractures and contusions being lead anatomic patterns.

- A survey of injured curlers demonstrated strong support for use of appropriate footwear as a key preventive strategy, but not for helmet wear.

\section{Introduction}

Curling is a popular recreational and competitive sport and a fundamental part of Canadian identity. ${ }^{1-3}$ Since the 1998 Winter Olympics, curling has been an official Olympic sport. Although the World Curling Federation comprises 49 member countries, Canadians make up about $80 \%$ of the worldwide curling population, with between 730000 and 870000 curlers. ${ }^{1,2,4}$ Yet there is little published information on occurrence of injuries.

Curling is played on ice. The object of the game is to slide a 20-kilogram stone on an ice sheet so that it comes to rest as close as possible to a target. Two teams, each made up of four members, alternate strategic throwing of these rocks. Team members alter the course of the stone by using brushes to sweep and thus melt the ice around the stone to reduce friction.

There are many opportunities for injury when curling. While the slipperiness of the ice is exploited in the game, balance, flexibility and experience are required to minimize risk of falls. Sweeping is vigorous and requires co-ordination while sliding and avoiding obstacles. ${ }^{5}$ Mastery of these techniques and skills can require years of dedicated practice.

Curling is generally perceived as a sport with a low risk for injury, though the published data are sparse and have concentrated on the competitive population. One study that focused on two national championships found that acute injuries resulting in "time loss," or athlete-exposures (AEs), occurred at a self-reported rate of 2 to 2.3 per 1000 games. ${ }^{4}$ At another

Author references:

1. Department of Emergency Medicine, University of British Columbia, Kelowna, British Columbia, Canada

2. Kingston General Hospital Clinical Research Centre, Department of Emergency Medicine, Queen's University, Kingston, Ontario, Canada

Correspondence: Daniel Ting, Kelowna General Hospital, 2312 Pandosy Street, Kelowna, BC V1Y 1T3; Tel: 250-980-1343; Fax: 250-980-1356; Email: daniel.ting@alumni.ubc.ca 
men's championship, acute injuries occurred at a self-reported rate of 3.5 per 1000 AEs. $^{6}$ At the 2010 Winter Olympics, the acute injury rate requiring medical attention was 2.5 per 1000 AEs; the two acute injuries happened to men while the women's bracket reported no injuries. ${ }^{7}$ Most of the injuries reported were sprains to the knee, back and shoulder; none specifically reported head injuries.

Curling uses sport-specific equipment to maximize performance and minimize injury risk. Proper sporting equipment includes a brush for sweeping and for stabilization when "delivering the rock" and sport-specific curling shoes called "grippers" and "sliders." These shoes not only enhance curling performance, but also reduce the risk of slipping when moving on the curling sheet. Whereas brushes are used universally, curling clubs often do not enforce the use of proper footwear for the recreational curler. Some recreational curlers use running shoes instead of grippers, and tape the soles of their shoes to permit sliding instead of using a proper slider. Head protection is not traditionally used in curling.

Several key questions about curling injuries remain unanswered. All studies to date have focused on elite, competitive curlers, who represent a small proportion of all curlers, and almost certainly have a different injury profile than recreational curlers. These previous studies have also examined smaller populations of curlers (100 or fewer) and have collected information at a single point in time. Attitudes of curlers towards equipment-based prevention strategies also remain unknown, but are essential to effective sports injury prevention. ${ }^{8}$

The aims of our observational, descriptive study are three-fold: (1) to describe the type and severity of injuries among recreational curlers; (2) to approximate the rate of acute curling injuries in a recreational population over several years; and (3) to assess curlers' attitudes to using equipment to prevent injuries.

This research study was given ethics approval by the Health Sciences Research
Ethics Board at Queen's University in Kingston, Ontario, Canada.

\section{Methods}

\section{Location of study}

Kingston is home to three curling clubs: the Royal Kingston, the Cataraqui and the Garrison Clubs. The Kingston community is served by two hospitals: Kingston General Hospital and Hotel Dieu Hospital. They are the only emergency departments (EDs) in Kingston, and each provides services to adults and children. Both have diagnostic radiology services and, unlike in many other Canadian cities, there were no walk-in clinics with X-ray services during the time of study.

\section{Population at risk}

The population at risk was estimated using membership counts of the three curling clubs in Kingston, which totaled 1184 in the year 2012 (Table 1). We assumed that the local membership counts were stable over the study period. Data were acquired through personal communication with membership administrators. Reports from Sport Canada show relatively stable national participation rates in curling in $1998(1.3 \%),{ }^{9} 2005(1.1 \%)^{10}$ and 2010 $(0.9 \%) .{ }^{11}$ We also assumed that injured curlers who presented to the Kingston General Hospital or Hotel Dieu Hospital were from one of the Kingston curling clubs. Age groupings assessed were 0 to 17 , 18 to 34,35 to 49,50 to 64 and 65 years and over.

TABLE 1

Membership count of Kingston curling clubs in 2012, by age and gender

\begin{tabular}{lccr} 
Age, years & Male & Female & Total \\
\hline $0-17$ & 83 & 36 & 119 \\
$18-34$ & 53 & 27 & 80 \\
$35-49$ & 70 & 65 & 135 \\
$50-64$ & 259 & 246 & 505 \\
$\geq 65$ & 218 & 127 & 345 \\
Total & 683 & 501 & 1184 \\
\hline
\end{tabular}

\section{CHIRPP database and chart review}

The Canadian Hospitals Injury Reporting and Prevention Program (CHIRPP) is an ED-based injury surveillance database established in $1990 .^{12}$ There are 15 participating hospitals across Canada: 11 pediatric and 4 general. When injured patients present to the ED of a participating hospital, they are asked to complete a one-page questionnaire describing the circumstances and mechanism of injury and to provide demographic information. Research staff record details on the nature of the injuries and treatments. Both Kingston General Hospital and Hotel Dieu Hospital participate in CHIRPP.

We identified potential participants for our study using two strategies. First, a specific code in the CHIRPP database identifies curling as the activity leading to injury. Second, we performed a text search for "curl" in the injury description. We searched for injuries during an 18-year period between 1993-10-1 and 2011-02-28. We then reviewed each retrieved entry and removed irrelevant or duplicate entries. We tried to identify acute curling injuries and disregarded chronic injuries related to curling.

After identifying study participants, we reviewed patient medical records to obtain further information on how the injury happened, what part of the anatomy was injured, the severity of the injury and the treatment.

\section{Secondary survey}

We identified curlers who had had an injury in the most recent decade of data availability (ending 2011-02-28). We searched medical records to identify those known to have died and exclude them from the survey. We identified 104 eligible curlers to whom we mailed a paper survey alongside a description of the survey goals. The survey asked about mechanism and causation of injury, attitudes towards equipmentbased injury prevention strategies, additional curling injuries and demographic characteristics. A reminder was mailed to non-responders six weeks later. There was no incentive for completing the survey. 
TABLE 2

Curling experience of secondary survey respondents at time of injury

\begin{tabular}{lccc}
\multicolumn{2}{c}{$\begin{array}{c}\text { AEs per week, } \% \\
(\mathbf{n}=\mathbf{4 9 )}\end{array}$} & $\begin{array}{c}\text { Years of curling experience, } \% \\
(\mathbf{n}=\mathbf{4 8})\end{array}$ \\
\hline$<1$ time & 22 & $<1$ & 17 \\
$1-2$ times & 39 & $1-3$ & 17 \\
$3-4$ times & 35 & $4-6$ & 13 \\
$>4$ times & 4 & $\geq 7$ & 54 \\
\hline
\end{tabular}

Abbreviation: AE, athlete-exposure.

\section{Statistical analysis}

Rate of injury was calculated by dividing the number of acute injuries by the number of AEs of the population at risk (Table 2). AEs were calculated by using the secondary survey data for games played per week and multiplied by length of the curling season. A curling season was counted as months that we captured more than 10 injuries. Statistical significance was assessed using chi-square tests. Rejection of the null hypothesis required $p<.05$.

\section{Results}

\section{Acute injury rate}

We identified 223 people with curling injuries. Of these, 208 were classified as acute rather than chronic injuries (Table 3). Six athletes had two independent curling injuries. The youngest curler injured was 7 years old. We captured significant curling injuries during seven months of the year. From the secondary survey, we obtained an average of 2.1 AEs per week (Table 2). We estimate an acute injury rate requiring ED presentation at 0.17 per $1000 \mathrm{AEs}(95 \% \mathrm{CI}$ : $0.12-0.22$ ).

TABLE 3

Demographic characteristics of curlers presenting to emergency departments with an acute injury, 1993-2011

\begin{tabular}{lccc} 
Age, years & Male & Female & Total \\
\hline $0-17$ & 6 & 7 & 13 \\
$18-34$ & 15 & 23 & 38 \\
$35-49$ & 19 & 23 & 42 \\
$50-64$ & 21 & 36 & 57 \\
$\geq 65$ & 37 & 21 & 58 \\
Total & 98 & 110 & 208 \\
\hline
\end{tabular}

\section{Injury characterization}

Table 4 presents a detailed listing of all injuries. Of the acute injuries, $92.7 \%$ were the result of falls on ice. There were two stereotypical patterns of falls: slipping backwards, resulting in an occipital head injury (28.1\%), or slipping forwards, resulting in a Fall On Outstretched Hand (FOOSH) injury (20.8\%). Together, these mechanisms accounted for $49.0 \%$ of falls.

Consistent with these mechanisms, the most common category for injuries following falls were head injuries, followed by wrist/hand injuries; together, they tallied $54.3 \%$ of the total of acute injuries
(Figure 1). Head impact injuries included 37 closed head injuries/concussions (Table 4), and $19.3 \%$ of injuries from falls.

\section{Attitudes towards injury prevention strategies}

Of the 104 mail surveys 13 were returned unopened. Of the 91 individuals who we presume received the survey, 49 returned completed surveys (54\%). The responding population did not differ significantly from the overall population by gender or age grouping $(p>.05)$.

Many of the injured were practised curlers; the majority (54\%) had at least

TABLE 4

List of acute curling injuries by anatomical grouping

\begin{tabular}{|c|c|c|c|}
\hline Site of injury & Description & $\begin{array}{c}\text { Number of injuries } \\
\text { documented }\end{array}$ & $\%$ \\
\hline \multicolumn{4}{|l|}{ Head } \\
\hline \multirow[t]{3}{*}{ Brain } & Closed head injury/concussion & 37 & 17.8 \\
\hline & Nerve injury & 1 & 0.5 \\
\hline & Intracranial bleed & 3 & 1.4 \\
\hline Skull & Soft tissue injury & 12 & 5.8 \\
\hline Face & Soft tissue injury & 13 & 6.3 \\
\hline \multicolumn{4}{|l|}{ Trunk } \\
\hline \multirow[t]{2}{*}{ Thorax } & Soft tissue injury & 9 & 4.3 \\
\hline & Fracture & 8 & 3.8 \\
\hline Lower Back & Soft tissue injury & 5 & 2.4 \\
\hline \multicolumn{4}{|l|}{ Upper arm } \\
\hline \multirow[t]{2}{*}{ Shoulder } & Soft tissue injury & 13 & 6.3 \\
\hline & Dislocation/fracture & 9 & 4.3 \\
\hline \multirow[t]{2}{*}{ Elbow } & Soft tissue injury & 10 & 4.8 \\
\hline & Fracture & 5 & 2.4 \\
\hline \multicolumn{4}{|l|}{ Wrist/hand } \\
\hline \multirow[t]{2}{*}{ Wrist } & Soft tissue injury & 11 & 5.3 \\
\hline & Fracture & 23 & 11.1 \\
\hline \multirow[t]{2}{*}{ Hand } & Soft tissue injury & 8 & 3.8 \\
\hline & Dislocation/fracture & 5 & 2.4 \\
\hline \multicolumn{4}{|l|}{ Lower body } \\
\hline \multirow[t]{2}{*}{ Hip } & Soft tissue injury & 3 & 1.5 \\
\hline & Fracture & 5 & 2.4 \\
\hline \multirow[t]{2}{*}{ Knee } & Soft tissue injury & 9 & 4.3 \\
\hline & Dislocation/fracture & 5 & 2.4 \\
\hline Lower leg & Fracture & 3 & 1.4 \\
\hline \multirow[t]{2}{*}{ Ankle/foot } & Soft tissue injury & 7 & 3.4 \\
\hline & Fracture & 4 & 1.9 \\
\hline Total & & 208 & 100.0 \\
\hline
\end{tabular}


FIGURE 1

Anatomical location of acute curling injury, divided by grouping

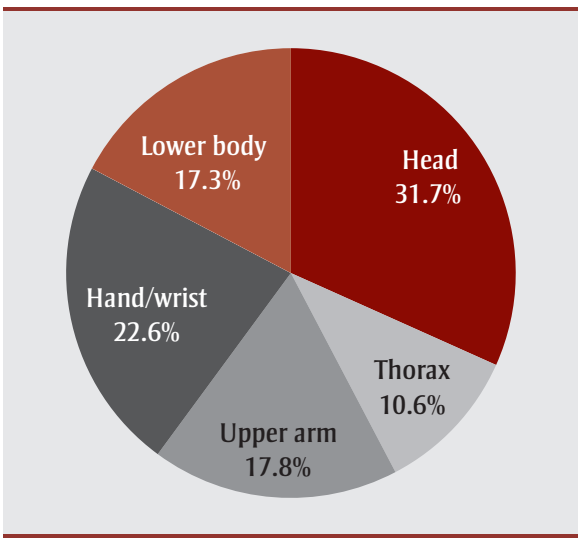

7 years of curling experience and curled between 1 and 4 times a week during the season (74\%) (Table 3 ).

As suggested by the results from the full data set, survey respondents attributed over $90 \%$ of their injuries to falls on the ice, most commonly due to the lack of proper curling footwear. $41.3 \%$ of survey respondents attributed their fall to a lack of proper footwear. Mandating use of proper footwear received support from nearly three-quarters of respondents (Table 5).

One survey question asked what participants thought about using helmets while curling. Whereas few respondents (8\%) thought helmets should be mandatory, $85 \%$ of respondents either believed in a use for helmets under certain circumstances (e.g. for learners, young children, curlers with disabilities) or that they should be recommended for general use (Table 5).

TABLE 5

Attitudes of secondary survey respondents towards curling injury prevention strategies

\begin{tabular}{lcc} 
& $\begin{array}{r}\text { Helmet } \\
\text { wear, \% } \\
(\mathbf{n}=\mathbf{4 8})\end{array}$ & $\begin{array}{c}\text { Curling-specific } \\
\text { footwear, \% } \\
(\mathbf{n}=49)\end{array}$ \\
\hline $\begin{array}{l}\text { Use unnecessary } \\
\begin{array}{l}\text { Use under certain } \\
\text { circumstances }\end{array}\end{array}$ & 50 & 0 \\
$\begin{array}{l}\text { Use generally, } \\
\text { recommended }\end{array}$ & 35 & 8 \\
\begin{tabular}{l} 
Use mandatory \\
\hline
\end{tabular} & 8 & 74 \\
\hline
\end{tabular}

The surveyed curlers did not significantly support the use of wrist guards, such as those used in snowboarding.

Though anecdotally associated with curling, we did not find alcohol use to contribute significantly to acute injury. Only one respondent believed that alcohol contributed to injury. Similarly, only 3 CHIRPP database and medical records documented alcohol as a factor.

\section{Discussion}

Our retrospective case series found that injuries in the recreational curling population were principally the result of falls, either through falling forward in such a way that resulted in a wrist injury or falling backwards, resulting in a head injury. We also found that injuries experienced by curlers can be serious and, most disconcertingly, involve brain injury. The rate of acute injury requiring ED presentation in the recreational population was 0.17 per 1000 AEs. The culture of curling at the recreational level does not rigidly enforce proper curling footwear, the lack of which curlers identified as a primary cause of falls.

About one-third of falls resulted in head injuries. Head injuries were not specifically reported in the literature on competitive curling, suggesting that this risk is higher within the recreational curling population. This would be logical, as recreational curlers, especially beginners, are less comfortable with sliding on the ice and at higher risk of uncontrolled falls. Similarly, backwards falls onto the head have been observed more frequently among beginner snowboarders compared to their seasoned peers. ${ }^{13}$

Recently, the scientific community has increased its attention towards the sequelae of sport-related concussions. ${ }^{14-15}$ The effectiveness of various means of head protection, however, remains unclear. Whereas helmets do reduce the risk of moderate to severe head injuries, current helmet designs may not prevent concussion. ${ }^{16-18}$ Furthermore, although our survey found that most curlers believe in a role for helmets, actual use is rare and stigmatized. Faced with similar chal- lenges, other sports have implemented changes to rules to reduce concussions. ${ }^{13}$ In curling, this approach could include mandating use of curling footwear, which improves control on the ice and thus may prevent falls and resultant head injuries altogether. As nearly half of our survey respondents attributed their fall to a lack of proper footwear, curling clubs should have little difficulty mandating the use of appropriate footwear and/or making it available on site.

In Kingston, one curling club has a policy that requires curlers aged 11 and under to use helmets. In our dataset, 8 injured athletes were younger than 11 . The literature suggests that the concussed pediatric athlete has a longer recovery time and different physiological response compared to older athletes. ${ }^{19-21}$ Other research suggests that females may also be at higher risk of concussion and have slower recovery times. ${ }^{22-24}$ Therefore, more aggressive prevention strategies may be indicated in these groups as well as among adult beginners.

\section{Strengths and limitations}

While our study identified a relatively small number of curling injuries, which permitted only a descriptive analysis, it is the most complete examination of acute curling injuries to date and is the first to describe injuries experienced by recreational curlers. We used an established injury surveillance program for ED-based care that identifies all injured people presenting to one of two settings serving a geographically distinct population. Given the low rate of injury occurrence, a prospective study design was less feasible. We also performed a secondary survey to enhance data available from CHIRPP and to ask for opinions related to injury prevention strategies. We identified head injury as making up a significant portion of acute curling injuries and, based on the survey responses, have identified a simple prevention strategy-mandated curling footwear use.

However, our results stem from a retrospective case series design and an approximation of the population at risk. Our injury estimates are likely conservative as 
we tracked only those people with injuries who sought care in an ED setting.

Our secondary survey was completed by only $54 \%$ of those receiving the survey. This small sample size was used to estimate AEs for recreational curlers. Further, although the gender and age profiles of survey respondents did match the overall Kingston curling population, all the curlers surveyed had been injuredmeaning that they might be more likely to support safety measures compared to those who have not been injured. Nevertheless, all survey respondents agreed with the use of some level of proper footwear while curling, and nearly three-fourths thought it should be mandated, suggesting that the attitude of the general curling population would be in favour of regulation.

\section{Conclusion}

Our study, based on a well-established injury surveillance program (CHIRRP), is the first to present information on injury occurrence and typology in recreational curlers. Most injuries occur by falling, with lack of proper curling footwear being reported as a key contributor.

We recommend that proper curling footwear be mandated and that curling clubs review their head protection policies, particularly among beginners and young curlers. For the ED clinician, the curlingrelated visit may present an opportunity to encourage players to use proper footwear to prevent future injury.

Future studies could further examine relationships between curling expertise and injury to better define the circumstances under which footwear and helmets would have the most benefit. A survey to assess attitudes of all curlers towards equipment-based strategies could also better characterize athlete opinion.

\section{Acknowledgements}

This study was supported by the Public Health Agency of Canada. Preliminary results of this research were presented at the 2013 Canadian Association of Emergency Physicians Conference in Vancouver, British Columbia, Canada.

\section{References}

1. Leipert BD, Plunkett R, Meagher-Stewart D, Scruby L, Mair H, Wamsley KB. "I can't imagine my life without it!” Curling and health promotion: a photovoice study. Can J Nurs Res. 2011 Mar;43(1):60-78.

2. Mair H. Curling in Canada: from gathering place to international spectacle. Int J Can Stud. 2007;35:39-60.

3. Wieting SG, Lamoreux D. Curling in Canada. Cult Sport Soc. 2001;4(2):140-56.

4. Reeser JC, Berg RL. Self reported injury patterns among competitive curlers in the United States: a preliminary investigation into the epidemiology of curling injuries. Br J Sports Med. 2004;38(5):E29.

5. Bradley JL. The sports science of curling: a practical review. J Sport Sci Med. 2009 Dec 1;8(4):495-500.

6. Berry JW, Romanick MA, Koerber SM. Injury type and incidence among elite level curlers during world championship competition. Res Sports Med. 2013;21(2):159-63. doi: 10.1080/15438627.2012.757229.

7. Engebretsen L, Steffen K, Alonso JM, et al. Sports injuries and illnesses during the Winter Olympic Games 2010. Br J Sports Med. 2010;44(11):772-80. doi: 10.1136/bjsm. 2010.076992 .

8. Finch CF, Donaldson A. A sports setting matrix for understanding the implementation context for community sport. Br J Sports Med. 2010;44(13):973-8. doi: 10.1136/bjsm. 2008.056069 .

9. Sport Canada. Sport participation in Canada, 1998 report. Ottawa (ON): Culture, Tourism and Centre for Education Statistics, Statistics Canada; 2000.

10. Ifedi F. Sport participation in Canada, 2005. Ottawa (ON): Culture, Tourism and the Centre for Education Statistics, Statistics Canada; 2008.

11. Canadian Heritage. Sport participation 2010. Ottawa (ON): Canadian Heritage; 2013.

12. Mackenzie SG, Pless IB. CHIRPP: Canada's principal injury surveillance program. Inj Prev. 1999;5(3):208-13.
13. Steffen K, Andersen TE, Krosshaug T, et al. ECSS position statement 2009: prevention of acute sports injuries. Eur J Sport Sci. 2010;10(4):223-36.

14. Harmon KG, Drezner JA, Gammons M, et al. American Medical Society for Sports Medicine position statement: concussion in sport. Clin J Sport Med. 2013;23(1):1-18. doi: 10.1097/JSM.0b013e31827f5f93.

15. Jordan BD. The clinical spectrum of sportrelated traumatic brain injury. Nat Rev Neurol. 2013;9(4):222-30. doi: 10.1038/ nrneurol.2013.33.

16. Abrahams S, Mc Fie S, Patricios J, Posthumus M, September AV. Risk factors for sports concussion: an evidence-based systematic review. Br J Sports Med. 2014;48(2):91-7. doi: 10.1136/bjsports-2013-092734.

17. McCrory P, Meeuwisse W, Aubry M, et al. Consensus statement on concussion in sport--the 4th International Conference on Concussion in Sport held in Zurich, November 2012. Br J Sports Med. 2013; 47(5):250-8. doi: 10.1136/bjsports-2013092313.

18. McIntosh AS, Andersen TE, Bahr R, et al. Sports helmets now and in the future. $\mathrm{Br} \mathrm{J}$ Sports Med. 2011;45(16):1258-65. doi: 10.1136/bjsports-2011-090509.

19. Field M, Collins MW, Lovell MR, Maroon J. Does age play a role in recovery from sports-related concussion? A comparison of high school and collegiate athletes. J Pediatr. 2003;142(5):546-53.

20. Kirkwood MW, Yeates KO, Wilson PE. Pediatric sport-related concussion: a review of the clinical management of an oft-neglected population. Pediatrics. 2006;117(4):1359-71.

21. Sim A, Terryberry-Spohr L, Wilson KR. Prolonged recovery of memory functioning after mild traumatic brain injury in adolescent athletes. J Neurosurg. 2008;108(3):5116. doi: $10.3171 / \mathrm{JNS} / 2008 / 108 / 3 / 0511$.

22. Broshek DK, Kaushik T, Freeman JR, Erlanger D, Webbe F, Barth JT. Sex differences in outcome following sports-related concussion. J Neurosurg. 2005;102(5):85663. 
23. Covassin T, Swanik CB, Sachs ML. Sex differences and the incidence of concussions among collegiate athletes. J Athl Train. 2003;38(3):238-44.

24. Dick RW. Is there a gender difference in concussion incidence and outcomes? Br J Sports Med. 2009 May;43 Suppl 1:i46-50. 10.1136/bjsm.2009.058172. 